\title{
Reasons to Reject Allowing
}

\author{
ALLAN GIBBARD \\ University of Michigan, Ann Arbor
}

The morality of what we owe to each other is a matter of principles that no one could reasonably reject-if we were all concerned to agree on what sort of conduct to allow or disallow. We care about it deeply, because we want to be able to justify what we do to others on a basis that they could not reasonably reject. I find this an immensely appealing moral ideal, and find Scanlon's explanation of its appeal plausible and illuminating. What We Owe to Each Other is a wonderful book full of deep and extended argument. No brief exploration could begin to do it justice, but I will touch on a few questions the book raises for me.

\section{Reasons}

Scanlon and I agree, for the most part, about the concept of a reason, though Scanlon speaks as a normative "realist", whereas I have called my own position a form of non-cognitivism. Scanlon is not a full-blown Platonist, for talk of a non-natural realm of reasons that we can intuit does not, on his view, do anything to explain reasons and our awareness of them. Still, apart from this, Scanlon's view of the concept of a reason may not be all that different from Moore's view of the concept of good.

On my own view likewise, if we look for a straight analysis of the concept of a reason, we will find none that works. I mean the concept of a reason to do something, as when I say that the health effects and addictiveness of smoking are reasons not to take it up. I don't mean the psychological concept of an "operative reason", as Scanlon calls it, a person's reason for doing what she does, as in "Her reason for taking up smoking was that it would freak out her parents;" saying this doesn't commit us to thinking that that's any reason at all to take up smoking. Now for this normative concept of a reason to do something, I agree with Scanlon: we can't do better than he does by way of straight analysis; we can only say, somewhat uninformatively, that to be a reason to do something is to count in favor of doing it. On much the grounds he lays out, for instance, we can't translate talk of reasons into psychological claims about preferences or desires. 
Still, just to leave matters at that, it seems to me, is to leave them mysterious. What is this notion of a consideration's "counting in favor" of an act? What are we claiming when we say such a thing? To be sure, even with no further explanation, I would go on using the notion of a reason, but it should leave me worried; I would be clinging to something I couldn't explain.

We can do better. Picture thinking what to do; consider it psychologically. I decide whether to eat the ice cream by weighing considerations for and against-quick enjoyment against later health, say. This concept of weighing is psychological; we know what it is for a person to weigh enjoyment in favor of eating. We can even think how a robot could be constructed to mimic such a process of weighing considerations and acting on the results. If we found another robot whose movements were shaped by a natural selection algorithm, we can comprehend what sorts of results would constitute, in effect, its weighing a consideration in favor of something. This concept of weighing is psychological and naturalistic.

Now the non-naturalist offers this much by way of explaining this psychology. In the first place, we have the general notion of a belief. Second, we have the concept of being a reason to do something, or counting in favor of doing it, a concept we understand but can't explain. To describe the person who deliberates, then, simply put these notions together: he believes that pleasure counts in favor of things and chances of death count against and count more. Now I do not reject this, but putting matters this way leaves room for questions we recognize as nonsensical, questions that have no answer except, "That's brutely the way things are." What is this quality of counting in favor, "out there" independently of who favors it and why? Why do whatever there's most reason to do? Why does this particular belief, that there's most "reason" to do so-and-so, play such a central role in action? Suppose an unfamiliar word had been used for all this, with no more explanation than we have given for reasons; we would be mystified. We could look at examples-but what would we recognize in them? Is the thing about reasons just that we know them when we see them, as with yellow? What is the peculiar attraction of reasons?

To understand what's going on with reasons, we should supplement this empty straight mode of explanation with an explanation of psychic role. Realize that deliberation will mimic a process of checking various facts and toting up scores in columns labeled with the names of alternatives, and then taking the alternative with the highest total. That's the psychic process of weighing considerations for and against. Not that all deliberation takes this simple weighing form, but start with the ones that do. What, then, of a person who found the notion of such a reason mysterious? At the end of this explanation, an explanation that begins with the psychic process of one's weighing a consideration for or against, we could say this to him: If you 
deliberate in this way, then you already believe certain things to be reasons for and against. You already know what it is to have such beliefs. And you can see that anyone who deliberates will form such beliefs. There's no more to believing something to be a reason than that-and it is a kind of belief that no one could renounce and still deliberate. ${ }^{1}$

To read Scanlon is to join him in thinking how to live a human life, and why. Pondering these matters is inescapable, a part of any normal human life-though pushing the demands of such thinking to philosophical extremes is avoidable enough. Thinking far or feebly on how to live, we do best to put our heads together, and to do that is to join each other in normative discussion. Scanlon engages us in an intricate inquiry into what constraints to accept and to demand for living together, for what reasons. However much he gets right or wrong, his project is intelligible and of central importance.

\section{Reasonable Rejection}

With Scanlon we search for a background rationale for morality. Utilitarians, many Kantians, and some kinds of contractarians hope for a full rationale, formulated in non-moral terms, from which more everyday precepts, whichever of them we should retain, can be drawn. Such a base level rationale is not Scanlon's ambition: He explains moral right and wrong only in terms of other morally charged notions. He relies on the notion of "reasonable rejection", and so a crucial puzzle is how much explanation we gain from this notion. One aspect of the puzzle is this: Scanlon uses his characterization of wrongness to argue that certain kinds of acts are wrong. To the extent that his conclusions agree with our considered judgements, these arguments can be seen as confirming his diagnosis of the morality of what we owe to each other. But Scanlon's derivations do not pretend to be algorithmic; he enjoys great freedom in the morally charged considerations he can draw on. Much rests on appeals to intuitive judgments of reasonableness. As Scanlon well realizes, then, a reader must worry about whether the derivations are fudged, whether considerations about reasonable rejection of principles let us derive conclusions about right and wrong just by drawing their plausibility from what we already think about right and wrong.

Consider a stock scenario: We settle a new land, and arrange a division of the land that we ranch. This division is fair: no one can reasonably reject it. It

I treat the concept of a reason in Wise Choices, Apt Feelings (1990), pp. 160-164. To call $R$ a reason to do $X$, I say, is to express one's "acceptance of norms that say to treat $R$ as weighing in favor of doing $X^{\prime \prime}(163)$. Scanlon discusses this (58): Normative reasons are beliefs, he maintains, and I am now happy to agree. Scanlon worries that to explain the concept of a reason, I appeal, in effect, to his own, normative notion of "counting in favor". But 1 intended my words "to treat $R$ as weighing in favor of doing $X$," in the psychological sense I have been expounding. 
is wrong, then, in the course of ranching, to violate the rules of property that this division sets up. Then oil is found under the land, offering far more wealth than can ranching in this country. The oil is under some ranches and not under others. Two possible sets of principles are now salient: Those with oil under their land say that rights to the oil go with their rights to ranch. That's sheer luck, they agree, but it's the way the rights of the matter happen to have worked out. Others say that the initial division wasn't with an eye to oil, and all are equally entitled to the unexpected benefits. What then do they owe to each other?

This is a classic bargaining situation in moral guise. Two arrangements are proposed: "to each his own" and equal sharing. If these are the only alternatives, then presumably, at most one side can be reasonable here in rejecting the arrangement less to its advantage--but which? If more alternatives come into play, there will still be an "efficiency frontier" on which anyone's gain is someone else's loss, and so like questions still arise. Here if anywhere, we might think, thoughts of reasonable rejection can help us to sort through the rights and wrongs. But how?

I can reasonably reject a set of principles, perhaps, just in case they allow me less than my due, if they impose excessive burdens on me in light of the burdens they impose on others or fail to demand enough of others on my behalf. So the question boils down to whether the oil is due to the lucky or due to all. But to say this seems to leave us asking directly what the rights and wrongs of the case are. I reasonably reject a set of principles, perhaps, if it burdens me by disallowing acts of mine that aren't wrong, or by allowing acts of others that are wrong, to my disadvantage in comparison to a just alternative. The just alternative is the one that disallows all and only acts that are wrong. All this, however, is to characterize "reasonable" rejection in terms of wrongness. Can thoughts of what's reasonable play a more independent role than this?

This is a question that Scanlon keeps addressing, and perhaps it can be answered only by considering his many particular arguments. This I won't attempt; instead, I move to a more specific worry.

Scanlon distinguishes narrow morality, in the sense of what we owe to each other, from broader ways in which we may reasonably want certain kinds of acts not to be performed. The brutality of bear-baiting isn't in the realm of what we owe to bears, and it isn't fully explained by considerations of what we owe to each other. Likewise for some of the waste of failing to develop one's talents. And for some realms that are central to "morality" as the term is widely used, such as sexual "morality", the story is complex: there's no reason to be appalled, say, by sodomy as such, and rape is of course a serious, narrowly moral wrong, a deep violation of what we owe to each other. Some ways of approaching sex, though, are dismaying without being of nar- 
rowly moral concern, a matter of what we owe to each other. These distinctions that Scanlon draws seem right to me. I want to explore, though, whether they fall out of Scanlon's system, and what kinds of resources we need in order to make these distinctions.

Suppose someone stands ready to reject any code whatsoever that allows bear-baiting. Then unless this stance is unreasonable, it follows that bearbaiting is wrong-in the narrowly moral sense. For there's then no universally unrejectable code that permits bear-baiting. And so if brutality of bearbaiting isn't a narrow wrong, in the sense of violating what we owe to each other, we'll need some account of why such rejection is unreasonable. Scanlon does discuss such issues, but as far as I can see, he rules out such rejection simply as not a matter of what we owe to each other. "I do no wrong to anyone" is one of his explanations of why I can't reasonably reject a principle (219-220). The exclusion of important values from the realm of what we owe to each other, then, doesn't fall out of the contractual theory; rather, the interpretation of contractual theory rests on a prior understanding of what falls under what we owe to each other. The same will go for failing to develop one's talents. Why can't someone reasonably reject allowing this? Scanlon regards it as one of the attractions of his theory that "all objections must be raised by individuals" (230). What, though, of objections that could be raised by an individual, but not on her own behalf.

There ought to be an answer, I agree, but I don't know how to draw it from Scanlon's contractual apparatus. We can reasonably reject principles allowing bear-baiting, I'd think, on behalf of the bears that would be baited. Indeed it looks as if what is needed in all these cases is to say that "reasonable rejection" is to be understood, in Scanlon's definition, as rejection that is both reasonable and on one's own behalf. If I reject bear-baiting, it isn't on my own behalf, and so its wrongness is not a matter of what we owe to each other. Scanlon himself rules out impersonal reasons for rejecting principles; but is this a consequence of his general contractualist formulation?

Scanlon might also have asked what agreeing to "allow" or "disallow" an action amounts to. If the force of "disallowing" something is that, costlessly, no one will ever do it, then we have reason to want such vices as smoking, the waste of talents, and the cheapening of the precious disallowed. If the force of "disallowing" is to turn sanctions of guilt and resentment on such acts, then we might not have sufficient reason to want these things disallowed, because the cure is worse than the disease. This is the kind of consideration that utilitarians bring to bear, as with Mill, and it looks as if they should be available to Scanlon. But he himself discusses such approaches only to reject them. I myself would insist that rejection is terribly unreasonable if it ignores the broad benefits and costs of alternative systems of allowing and disallowing. To ignore the psychic cost of a moral system is 
to treat human suffering cavalierly. I hope that Scanlon's formula is properly interpreted as taking such costs and benefits seriously.

To distinguish the realm that Scanlon is marking out, it thus seems, the concept we need is this: reasonably rejecting a code on one's own behalf, or for reasons that are personal. This concept may not fit smoothly into Scanlon's project. His Chapter 3 is a marvelously crafted critique of any uniform notion of a person's good or a person's self-interest. No one concept, he argues, can meet all the demands placed on a notion of a person's interests. One of these demands is to mark out which considerations one can legitimately claim to have counted morally on one's behalf. This, however, is something that must emerge from a moral theory; it can't be a starting point for moral theorizing. We have now seen, however, that what counts as the right kind of rejection of a code, be it reasonable or not, depends on the notion of an objection on one's own behalf. This doesn't just emerge from the theory, but is a crucial ingredient

\section{Contractualism and Bargaining Theory}

Contractarianism comes in a family of versions that Scanlon distinguishes from his own "contractualism". In a form that draws heavily from economists' bargaining theory, these theories propose something like this: standards of justice and of right and wrong are the ones that would be agreed to in fair circumstances. Scanlon himself rejects such contractarianism at least in part because he rejects its notion of utility, a person's good on a unidimensional scale. Scanlon does, if I am right, need a notion of reason to prefer on one's own behalf, but whether this can be placed on a unidimensional scale is a question far beyond the scope of a quick treatment. We can ask, though, whether Scanlon's differences from "contractarianism" proceed entirely from this difference on the formal properties of one's most fundamental reasons for policy.

Standard bargaining theory proceeds in terms of what one has reason to insist on, in the face of others' acting on their own reasons to insist otherwise, and given everyone's reasons for preferring various agreements to none at all. Is this Scanlon's picture? Not as he applies his method, certainly. His discussion of aggregating the costs and benefits of different people, for instance, studiously ignores all questions of $e x$ ante appeal of different possible social arrangements, of reasons to prefer before knowing who occupies which position (229-241). This kind of thing is meat and drink to some important economics-inspired social arguments. Scanlon's own arguments rest instead, to a substantial degree, on direct intuitions of what are acceptable arrangements. But is he constructing a system that within which he should be taking such economic style arguments seriously? 
Much will hinge on what the term 'reasonable' means. On one reading, we can explain something's being reasonable in terms of a general notion of reasons-valid reasons to do something. What's reasonable is perhaps what's most supported by reasons. Or, Scanlon suggests, it's a matter of what's supported by reasons within a contextually determined range. For purposes of "reasonable rejection", these might be reasons to prefer one code to another on one's own behalf, together with reasons to come to agreement with others similarly motivated. If this is the right reading, it looks much like a realization of standard bargaining theory, where parties are presumed to be moved by reasons of this kind. The ex ante appeal of social and moral arrangements should matter then greatly; how close this would bring Scanlon to utilitarianism is a large question.

Another suggestion of the term "reasonable", though, is morally laden from the start; Rawls's use of the term plays on this suggestion. If I am less accommodating than I should be, then I am being "unreasonable", whereas if I am more accommodating - even if I am bargaining with the devil on behalf of the forces of good-we wouldn't normally say that I'm being unreasonable. We might instead say I'm being "more than reasonable". 2 Scanlon sometimes says that moral force is built into the word 'reasonable' as he is using it, and his appeals to the notion are not always attempts to demonstrate that one's reasons on one's own behalf and reasons to reach accommodation work on their own to produce the outcome Scanlon derives. Sometimes what he appeals to is that a principle is unfair, that it singles others out, without justification, for privileged status (217).

At the start of the book, Scanlon introduces the idea of reasonableness in a way that fits the first sense, as responsiveness to a range of reasons, such as those grounded in other peoples' interests. With talk of reasonable rejection, "What we are claiming is that there is reason to take these interests into account given the supposed aim of reaching agreement..." (33). If this is what he means by the term when he gets to applying it, however, we need more explanation. That rejection is reasonable, Scanlon now tells us, "is a judgment with moral content" (217). Since this content grounds the entire system, we need to understand what it is. Scanlon is right, I am convinced, about a crucial source of moral concern. Whether identifying this source of concern has helped us settle the shape and content of moral demands is a question I find puzzling. 